\title{
THE EFFECT OF MOBILE AR APPS ON PURCHASE INTENTIONS OF RETAIL CONSUMERS: A STUDY ON THE MEDIATING ROLE OF PERCEIVED RISK
}

\author{
DOI: 10.17261/Pressacademia.2021.1400 \\ RJBM- V.8-ISS.2-2021(4)-86-100
}

\section{Edin Guclu Sozer}

Istanbul Okan University, Department of Business Administration, Tuzla, Istanbul, Turkey. edin.sozer@okan.edu.tr, ORCID: 0000-0003-4984-4629

\begin{tabular}{l}
\hline Date Received: April 11, $2021 \quad$ Date Accepted: June 9, $2021 \quad$ open OCCESS \\
\hline To cite this document \\
Sozer, E.G., (2021). The effect of mobile AR apps on purchase intentions of retail consumers: a study on the mediating role of perceived risk. \\
Research Journal of Business and Management (RJBM), 8(2), 86-100. \\
Permanent link to this document: $\underline{\text { http://doi.org/10.17261/Pressacademia.2021.1400 }}$ \\
Copyright: Published by Press Academia and limited licensed re-use rights only. \\
\hline
\end{tabular}

\section{ABSTRACT}

Purpose - The objective of this study is to identify the factors which contribute to the effectiveness of Augmented Reality (AR) apps on generating favorable consumer responses and to investigate the mediating role of perceived risk on this effect in the retailing context.

Methodology - A field study is conducted with 144 participants who plan to buy a sports shoe product. Subjects are introduced an AR app to test the sports shoes in digital format in their physical home environment and then they are asked to fill-out the questionnaire measuring the effect of using AR in their shopping experience and purchase intentions.

Findings- The results of the study confirmed the positive and significant influence of AR app features including perceived augmentation, utilitarian, and hedonic benefits on decision comfort level of customers. In turn, the decision comfort is found to be positively influencing the purchase intention. The perceived risk related to the product is found to have a mediating effect on the impact of decision comfort on purchase intention. Conclusion- The study reports a positive impact of AR app experience on retail purchases. In the light of the findings, some academic and managerial implications are provided.

Keywords: Augmented reality, perceived augmentation, AR benefits, purchase intention, perceived risk JEL Codes: M30, M31, M39

\section{INTRODUCTION}

Technological developments occurred since the mid of the 20th century caused to radical transformations in many industries by shaping the structure of their ecosystems and business models, which, in turn, resulted in changes at the operational, organizational as well transactional levels of the business. Retailing is one of these industries which was subject to dramatic changes, especially in the last two decades, as a result of the introduction of online channels and an uninterrupted digitalization process. Retail industry witnessed a very rapid transition from single to multiple and then to omni channel structures involving the integration of online and offline retailing through physical stores, service centers, personal computers, tablets as well as mobile phones. Following the introduction of interactive technologies that can be applied in these channels, retailers adopted these new technologies to their omni-channel structures to enhance the shopping experiences of their target consumers, leading to the new ways of engagement in their shopping activities (Yadav \& Pavlou, 2014). The evolution of Web 2.0 and 3.0 technologies provided the opportunity to generate interactive environments connecting retail customers to the company and to the rest of the consumer groups through online communities, social media, and smartphone apps (Ström et al. 2014; Kozinets et al. 2010).

One of the tools which generate an interactive environment for consumers supporting them in their online shopping experience is the Augmented Reality (AR) technology. Basically, AR technology serves as a tool to supplement the real-world environment with some virtual objects generated by the computer and real and virtual objects are being presented together generating an interactive environment by aligning these objects with each other (Azuma et al, 2001). The utilization of AR technologies in 
marketing field increased dramatically in recent years and this technology became a new way of presenting the offerings to the buyers in real environment settings (Huang \& Liao, 2015). It is also believed that this new technology will play a critical role on consumer decision making in the future. Markets and Markets (2015) estimated the total size of AR technology industry to reach at $\$ 56.8$ billion at the end of 2020 . Parallel to this estimation, Fortune also expected that the total revenue generated by $A R$ applications will be hitting to $\$ 120$ billion as the end of 2020 (Gaudiosi, 2015). However, as a technology investigated under the Human-Computer interaction $(\mathrm{HCl})$ as well as Computer-Vision areas, as a research topic, its impact on consumer behavior and how consumers react towards this new technology is one of the subjects neglected in the previous research agenda (Yadav \& Pavlou, 2014). Previous research conducted on this area focused mainly on the factors which lead to the successful adoption of AR applications. Most of these studies employed traditional technology acceptance models (TAM) to explain the adoption mechanism related to the AR applications (Pantano \& Servidio, 2012; Lee et al. 2006). Other two research streams focused on the impact of AR features as well as consumer traits on consumer responses towards the stimuli (Watson et al. 2020; Huang \& Liao, 2017). Although all these studies provide important contribution to the understanding of the adoption mechanism as well as its impact on consumer responses, there are still gaps in the literature which needs to be filled with further investigation.

One of the important factors, which is expected to be influential on consumer responses when AR applications employed in the purchasing process, is the perceived risk related to the product decisions. A review of relevant literature shows that previous studies which measure the impact of AR applications on consumer responses did not include perceived risk as one of the factors which influence the process. Therefore, this study targets to contribute to the marketing literature by extending the coverage of previous studies and including perceived risk as one of the factors which is expected to influence product purchasing decisions of consumers in AR assisted processes. Specifically, this study targets to identify those application features contributing to the effectiveness of the AR app in terms of providing decision comfort of consumers leading to favorable behavioral responses by taking into consideration the mediation effect of perceived risk on the impact of decision comfort on purchase intention. The investigation of mediation impact of perceived risk on the impact of decision comfort on purchase intention is the main contribution of this study.

In the following section, related concepts, review of previous studies, theoretical framework and hypothesis are provided. In the third section, the research methodology is explained in detail. Following the presentation of the findings, managerial as well as academic implications are provided. In the final section, some limitations related to the study and recommendations for further research are presented.

\section{LITERATURE REVIEW}

Augmented reality (AR) technology reached at the stage of stepping out from the laboratory settings to the real-world business applications since 1950's. The first applications of AR technology roots back to 1950's when Morton Heilig, specialized in cinematography, generated some special cinema features called as "Sensorama" (Carmigniani et al., 2011). During 1960's the first prototype of holographic projection was developed at Harvard University and this prototype enabled the user to see the 3-D graphics. In the following three decades, the focus on the AR technology was accelerated leading to developments in the virtual reality and mobile technologies as well as increasing the adoption rate of this technology in different fields including medicine, military, industry, gaming, education, and tourism (Javornik, 2016a). In 2008, one of the commercial applications of AR was realized in the automotive industry when Mini brand provided a 3-D simulation of the car model for the consumers. In addition to 3-D simulations, wearables like virtual try-ons or Google Glass on web sites, and content augmentations applications were also provided to consumers (Azuma et al. 2001).

\subsection{AR Adoption Process}

Increasing adoption of this technology in business settings, led to the rise of academic studies conducted to investigate this new interactive technology. One of the main streams of research on this subject was the determination of adoption factors and the role of AR features in this adoption process. A widely focused model in studies investigating the adoption of new technologies in retailing context is the technology acceptance model (TAM). Likewise, those studies focusing on the adoption mechanism of AR technology in retailing context also focused on the TAM. Originally developed by Davis (1986), TAM includes four types of constructs, namely perceived usefulness, perceived ease of use, attitude, and behavioral intention to use, to explain how a user becomes motivated to adopt a new technology. According to the Rese at el. (2017), from theoretical perspective, TAM relies on the basic Stimulus-Organism-Response model modified through the theory of reasoned action developed by Fishbein and Ajzen (1975). In the light of this theoretical framework, many studies investigated the factors leading to the acceptance of AR apps in a retailing context. Lee et al. (2006) focused on the acceptance of virtual-try-on app for clothes and investigated the impact of 
hedonic and utilitarian shopping orientations, level of image interactivity technology and TAM constructs on behavioral intention of consumers. In a similar study using virtual-try-on app for clothes, Kim, and Forsythe (2008) investigated the impact of technological anxiety, innovativeness, and TAM constructs on the behavioral intention as well as post-use evaluation of consumers. Huang and Liao (2015) investigated the impact of presence, perceptions related to the aesthetics, and playfulness, as well as excellence in service, behavior related to the sustainment of the relationship and TAM constructs to explain the adoption process of virtual-try-on app for clothes. In their study, Domina et al. (2012) focused on the virtual world composed of fashion sites and investigated the impact of perceived concentration, consumer innovativeness, perceived control, and TAM constructs on the intention to shop. In another study, Spreer and Kallweit (2014), focused on the book catalogue app and investigated the effect of information offer, information completeness and TAM constructs on behavioral intention. On the other hand, Kim and Hyun (2016) focused on the navigation app, and investigated the impact of information quality, service quality, system quality, and telepresence on the behavioral intention. Finally, Rese et al. (2017), employed a modified version of TAM and investigated the impact of perceived innovativeness, perceived enjoyment, and TAM constructs on the behavioral intention to use for two categories of AR apps including magazine (live) and home furniture.

\subsection{Influence of AR Technology on Consumer Perception and Responses}

Several studies focused on the characteristics of AR technology which are expected to generate positive consumer responses. The AR features or characteristics which are focused on the literature include interactivity, modality, augmentation, connectivity, location-specifity, mobility and virtuality, as the determinants of consumer responses. In their study, Poushneh and VasquezParraga (2017) investigated the role of interactivity on generating user experience, satisfaction, and purchase intention by implementing an experimental design where the manipulated factor was the level of interactivity provided by AR application. The results of the study confirmed the positive effect of interactivity and augmentation on the user experience and user experience is found to be effective on customer satisfaction and purchase intention. In another study, Javornik (2016b), investigated the effect of perceived augmentation on cognitive, affective, and behavioral responses of consumers. The author confirmed the positive influence of interactivity and perceived augmentation through the mediation of flow state. Jin (2009) focused on the modality feature of AR applications and measured the effect of product involvement and modality richness on the product evaluations as well as buying intentions and online shopping enjoyment in the 3D virtual store settings. The results of the study confirmed the moderating role of product involvement on the effect of modality richness on product evaluations, buying intentions and shopping enjoyment.

Several other studies focused on the influence of AR adoption on consumer perceptions as well as responses within the retailing context. In their study, Olsson et al. (2013) focused on the consumer perceptions and expectations related to the mobile augmented reality (MAR) applications. The authors targeted to measure the expectations regarding the expected MAR experience and user requirements. Findings of the study confirmed that consumers developed several cognitive and emotional benefit associations related to MAR applications including enhanced awareness, product knowledge and stimulating experiences. Rauschnabel et al. (2019) focused on the influence of augmented reality marketing on the brand attitude of consumers through perceived benefits and augmentation quality of AR apps. Authors confirmed the positive influence of AR apps on changing the brand attitudes. In another study, Li et al. (2002) investigated the effect of AR applications in the format of 3-D advertising on the attitude towards an online retailer through an experiment in a laboratory setting. Findings of the study confirmed that 3-D advertising influenced positively the brand attitude of consumers towards the retailer. Some other studies focused on the behavioral responses of consumers when they are exposed to AR applications. Hilken et al. (2017) investigated the influence of service augmentation on consumers' online service experiences which is expected to lead behavioral outcomes. Findings of the study confirmed that use of service augmentation applications increase value perceptions of the online service experience which in turn together with decision comfort, increases behavioral intentions. In another study, Beck and Crie (2016) investigated the influence of employing AR virtual fitting rooms on the purchase intentions of consumers. It is confirmed that the usage of AR applications increases the purchase intentions of consumers both in online and offline settings. Dacko (2016) focused on the influence of mobile AR applications in the retailing context on the several experiential shopping benefits and behavioral intentions. Positive influence of mobile AR applications are reported on the overall shopping experience, knowledge accuracy, decision certainty as well as behavioral intentions. In another study, Poncin and Mimoun (2014) investigated the effects of AR applications on consumer perceptions regarding the store atmospherics, affective reactions, and perceived shopping value in a physical retail environment by conducting a field study. The results of the study confirmed both the influence of these three constructs on store atmospherics, and also the positive influence of store atmospherics on customer satisfaction through the affective reactions and 
perceived shopping experience. Overall, previous studies provide sufficient level of confirmation regarding the positive influence of AR applications on cognitive, affective, and behavioral dimensions of consumer behavior.

\subsection{Theoretical Framework}

This study incorporates Stimulus (S), Organism (O) and Response (R) model originally developed by Mehrabian and Russell's (1974) to explain the impact of AR application on consumer perceptions and responses. SOR model is used to explain the flow for the generation of a consumer response when he or she is exposed to a stimulus. When an exposure to a stimulus (S) occurs, the person $(\mathrm{O})$ is expected to develop some internal states including emotions or perceptions and these in turn trigger some responses $(\mathrm{R})$. There are many studies in the literature which implemented the SOR model into the retailing context. Donovan and Rossiter (1982) predicted the effects of in-store atmosphere on shopping behavior by utilizing SOR model and the findings of their study confirmed the positive effect of store atmosphere on generating emotional states which were reported as the mediators of purchase intentions. Huang (2012) incorporated the SOR model into the social networking context and investigated the effects of environmental features on the online experience and purchase intentions. The results of the study confirmed the positive effects of social identity on cognitive and affective involvement which in turn influenced purchase intentions. In a similar study, Wu et al. (2013) adopted SOR model to investigate the effects of the design related to the layout of website store and the store atmosphere on the behavioral intentions of consumers. Results confirmed the positive effects of store atmosphere and layout design on the emotional arousal. Parallel to the studies which are adopted SOR model to explain the impact of various factors on consumer perceptions and reactions, this study incorporates also the SOR model into the AR context. Specifically, three important characteristics of AR applications, namely augmentation quality, utilitarian, and emotional benefits, are incorporated as the features of the Stimulus (S). On the other hand, two internal states, the consequences of exposure to the Stimulus (S), namely perceptions of decision comfort and perceived risk are incorporated as Organism (O) and purchase intentions toward the offered product is incorporated as the Response $(R)$.

\subsubsection{Stimulus Characteristics (S) and Consumer Decision Comfort (O)}

The differentiating feature of the AR technology in comparison to other interactive technologies is its ability to augment the physical environment with virtual features. This superimposition of the physical environment may be realized by employing different media elements ranging from pure text to image, audio, or video (Fitzgerald et al. 2013). Thus, as a new category of media features, augmentation, provides the opportunity to interact with the real environment in real time and this makes it a unique feature of AR apps which leads to a more intense flow of consumers into the reality compared to other interactive technologies (Javornik 2016b). When an AR app results in an experience perceived as authentic, this is reflected into the feeling of spatial presence leading to the increasing experiential value, which, in turn, is empowered by the simulated control over and inclusion into the physical environment provided to the customers as the means to engage into the shopping (Hilken et al. 2017). According to the Lombard and Snyder-Duch (2001), spatial presence is a type of psychological state, which involves the neglection of technological effects in an experience, and this situation eventually causes to the increasing feeling of physical environment leading to higher experiential value, more positive evaluation of product attributes and attitude towards the products (Klein, 2003; Fiore et al. 2005). In line with positive contributions to the experiential value, spatial presence is also expected to be influential on the decision-making process. Previous studies confirm that, in addition to have an experiential value, consumers adopt AR technologies also to reduce the uncertainty related to their decision (Dacko, 2016). Thus, they look for a sort of decision comfort, which can be defined as "the degree to which customers feel at ease with a specific decision", and it is influenced by affect laden cues (Parker et al. 2016). Since higher levels of perceived augmentation is associated with the feeling of spatial presence, and spatial presence is an affect laden cue (Hilken et al. 2017), it is expected that perceived augmentation will have an influence on the decision comfort perception of consumers. Based on this expectation, the following hypothesis is presented:

H1: Perceived augmentation of the AR application will have a positive effect on Decision Comfort.

When the retailing context is considered, two types of benefits, namely utilitarian and hedonic, are regarded as the determinants of consumer reactions towards the offering. Previous research studies conducted in the retailing context categorized functional and instrumental benefits related to the offerings under the utilitarian benefits, while aesthetics, enjoyment-related and experiential benefits are regarded as hedonic benefits which jointly generate the customer value of the offering (Chitturi, 2008). Several studies in the literature investigated the impact of utilitarian and hedonic benefits on the consumer decision making. In their study, Bauer et al. (2006) focused on the factors influencing service quality perceptions in online shopping. Two of the five quality dimensions which is expected to influence the service quality perceptions were functionality/design and enjoyment. Similarly, Childers et al. (2001) investigated the impact of utilitarian and hedonic motivations on shopping engagement in e- 
retailing context and reported the significant influence of bout types of benefits. Parallel to the findings of the previous studies, utilization of AR applications is also found to be positively influential on consumer experience perceptions taking into the consideration the level of utilitarian and hedonic benefits provided by the application (Poncin \& Mimoun, 2014). The positive contribution of AR applications on the mitigation of mental burden related to the imagination of the offered product in the physical environment and provides an opportunity for consumers to evaluate the offering in this physical environment setting (Hilken et al. 2017). Thus, it is believed that utilization of AR application and utilitarian and hedonic benefits provided by this application provide a decision comfort for the consumers in their shopping experience. Based on this expectation, the following hypotheses is presented:

H2: Utilitarian benefits provided by the AR application will have a positive effect on Decision Comfort.

H3: Hedonic benefits provided by the AR application will have a positive effect on Decision Comfort.

\subsubsection{Consumer Decision Comfort (0), Risk Perception (O) and Purchase Intention (R)}

One of the factors, which is considered as one of the several determinants in the decision-making process, is the risk level perceived by the consumer regarding the consequences of their behavior. Perceived risk involves the probability of loss due to the negative consequences of an action which are expected to generate a cost for the consumer in a shopping context (Bauer, 1960). The uncertainty about the consequences of purchasing a product determines the level of perceived risk and once the uncertainty level increases, risk perception becomes higher (Hong \& Cha, 2013). As a multidimensional construct, perceived risk is categorized under six dimensions including physical risk, convenience risk, financial risk, performance risk, social risk, and psychological risk (Murray, 1991). When we consider a purchasing situation, all these dimensions regarding the perceived risk have the probability of occurrence depending on the product category and the context which the shopping transaction occurs. Whatever is the type of risk involved, the main factor which leads to increasing risk perception is the uncertainty about the outcomes of the purchasing decision. According to Koller (1988), consumers perceive the situation as risky when the outcome may generate negative consequences and the person is not able to control these consequences. The inability to control the consequences, is expected to increase the risk perception related to the decisions considered. In a typical purchasing situation, the probability of negative outcomes, which are expected to generate additional costs, are subject to mitigative actions by consumers through the utilization of several factors. In the retailing context using AR technology, one of these factors is believed to be the decision comfort provided by the AR apps since it is expected to reduce the uncertainty by providing the ability to alter the environment and control of the senses (Dacko, 2016; Riva et al. 2016). Thus, it is believed that decision comfort level provided by the AR app will have a mitigating effect on the perceived risk level of consumers. In addition to its effects on the perceived risk level, decision comfort is also expected to have a positive effect on the purchase intention of consumers. When consumers feel a decision comfort in a decision-making process, this is expected to generate a positive outcome in terms of purchase intentions since it provides the required inputs for decision making, helps reducing the uncertainty and generates a soft-positive affective response towards the purchasing experience (Hilken et al. 2017). Purchase intention is a measure which helps to anticipate consumers' buying behavior in a purchasing situation (Li et al. 2002). This measure involves their interest as well as the possibility to buy a specific product and it is found to be strongly related to the future purchase action (Kim and Ko, 2012). Thus, it is believed that decision comfort level provided by the AR app will have a positive impact on the purchase intention of consumers. Based on this expectation, the following hypotheses is presented:

H4: Higher levels of Decision Comfort will lead to lower levels of Perceived Risk.

H5: Higher levels of Decision Comfort will lead to higher levels of Purchase Intention.

Previous studies confirm that when perceived risk becomes higher, consumers prefer to avoid taking an action and this situation generates a negative impact on purchase intentions (Pavlou, 2003; Jarvenpaa \& Leidner, 1999). Thus, it is strongly believed that increasing levels of perceived risk will lead to hesitations of consumers related to the purchase intentions for the product considered. Moreover, taking into consideration the expected positive direct effect of decision comfort on purchase intentions and the negative direct effect of perceived risk on the purchase intention, perceived risk level of consumers regarding the purchase situation is expected to have a mediating role on the influence of decision comfort on purchase intentions. Based on this expectation, the following hypotheses is presented:

H6: Higher the Perceived Risk is, the lower will be the Purchase Intention.

H7: Perceived Risk level will have a mediating role on the impact of Decision Comfort on Purchase Intention. 
Figure 1 includes the conceptual model and the hypotheses proposed to measure the impact of stimulus characteristics on decision comfort $(\mathrm{H} 1, \mathrm{H} 2, \mathrm{H} 3)$, the effect of decision comfort on perceived risk (H4) and purchase intentions (H5), and the effect of perceived risk on purchase intentions $(\mathrm{H} 6)$. The hypothesis related to the mediating effect of perceived risk on the effect of decision comfort on purchase intentions $(\mathrm{H} 7)$ is not presented in the conceptual model.

Figure 1: Research Model and Hypotheses

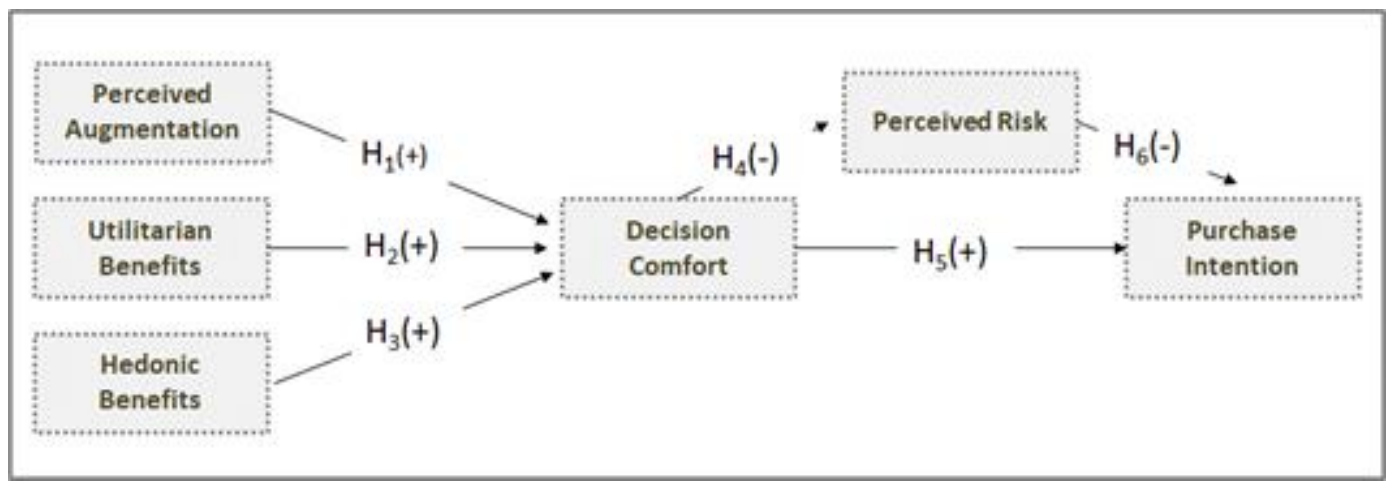

\section{RESEARCH METHODOLOGY}

\subsection{Research Design}

The main target of this study was to investigate the impact of AR app features on providing a decision comfort for the consumers and to measure the mediating role of perceived risk on the influence of decision comfort on purchase intentions. Sport shoes was determined as the product category of the study and the stimulus was the AR app called "Wanna Kicks" which is a digital platform to test the models of different sport shoe brands. To test the hypotheses proposed, a field study was conducted where the participants were the students from different universities in the prominent cities of Turkey. The sample group was composed of 144 participants with 79 male and 65 female consumers, who are interested with sport shoes products.

The study is conducted in two phases. In the first phase, respondents were explained that they will be presented an AR app which will help them to test different models of sport shoes offered by several brands on their feet in their physical environment. In order to be able to use the app on their mobile phones or tablets, participants were provided a link to download the app and required instructions to be able to use it in their physical environment. Following the successful download of the AR apps, participants were asked to check the products in the collection and try out sport shoe models in their physical environment. In the second phase of the study, participants were asked to answer the statements in their questionnaires and completed the submission process through online survey platform. The sample screenshots of AR app employed are presented in Figure 2. 
Figure 2: Wanna Kicks Mobile Augmented Reality (AR) Application Screenshots
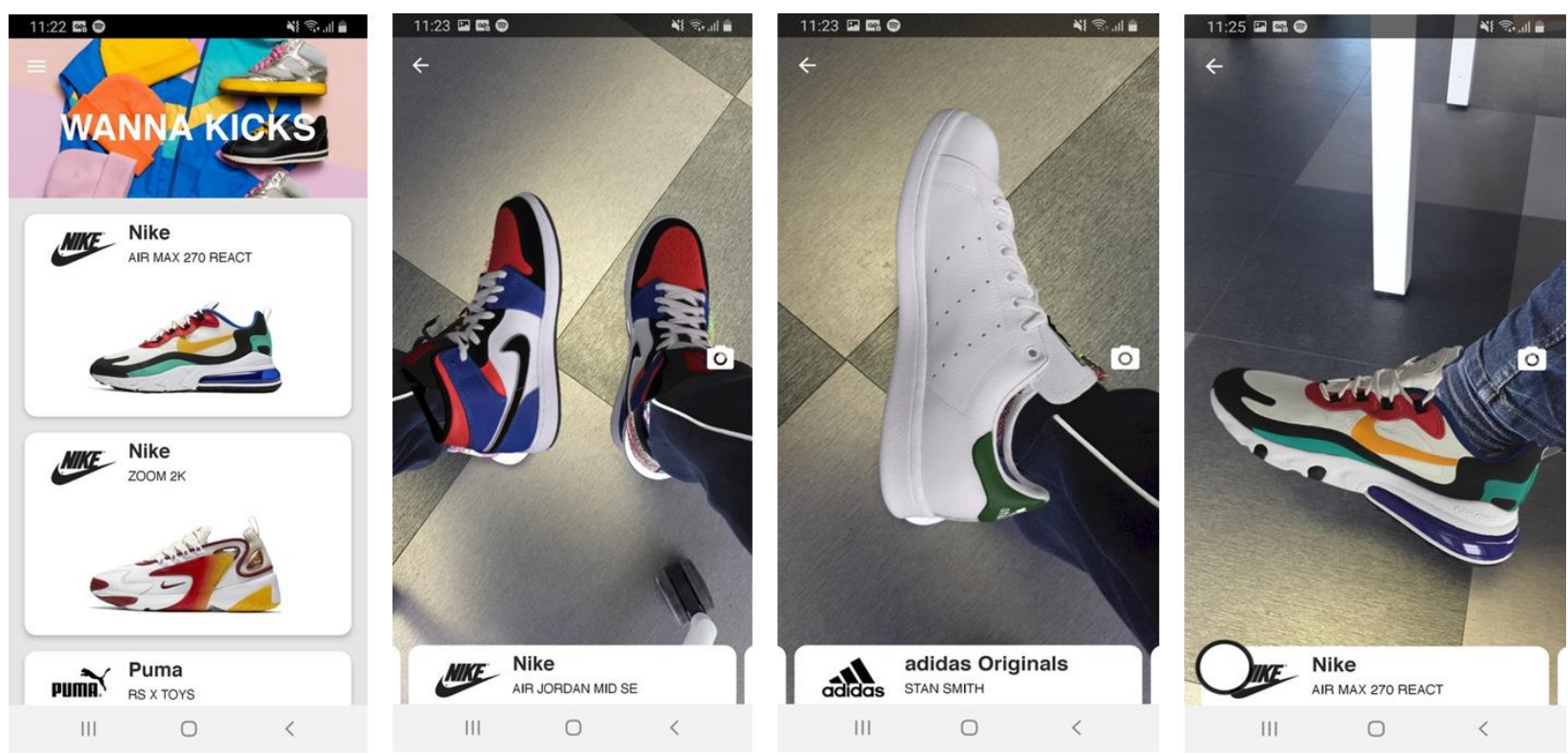

The analysis section was composed of two sections. In the first section, the validity and reliability checks for the scales employed in the model were conducted. The validity and reliability confirmations of the scales were followed by the testing process of hypotheses. Testing of the hypotheses was executed through the Structural Equation Modeling (SEM) using IBM SPSS and IBM SPSS AMOS software, version 27.

\subsection{Operationalization of Variables}

In order to measure the variables in the research model, the scales employed in the relevant literature are borrowed. Due to the original language difference, all scales borrowed were translated into the Turkish language. Perceived augmentation, utilitarian benefits and hedonic benefits scales are borrowed from Rauschnabel et al. (2019). All scales were measured using seven-point Liker-type scale. The authors adopted the three-items perceived augmentation scale from the studies of Hilken et al. (2017). On the other hand, two-items utilitarian benefits scale was adopted from the studies of Rauschnabel (2018) and Venkatesh et al. (2012). Finally, three-items hedonic benefits scale was borrowed from Venkatesh et al. (2012). Decision comfort scale was borrowed from Hilken et al. (2017) who borrowed the original scale from the study of Parker et al. (2016). The five-items scale employed was measured using five-points Likert Type scales. For the purpose of this study, the scale was converted into the fouritems scale by eliminating the reverse question. Perceived risk scale, which is a four-items semantic differential scale, was adopted from the study of Campbell and Goodstein (2001). For the purpose of this study, the scale was converted into the three-items scale by eliminating one statement which is found to be similar to another statement in the scale during the face validity checks. Finally, seven-point Likert Type purchase intentions scale was adopted from the study of Javornik (2016b) who borrowed the scale items from the study of Van Noort et al. (2012). Scale validation and reliability checks for all the scales employed in this study were done and confirmed by the respective authors. The scales and the associated scale items employed in the study are presented in Table 1. 
Table 1: Operationalized Variables and Scale Statements

\begin{tabular}{|c|c|c|}
\hline Variables & Items & Item Statements \\
\hline \multirow{3}{*}{ Perceived Augmentation } & AUG1 & I perceived like the shoe was a natural part of the physical environment \\
\hline & AUG2 & It seemed as if the shoe had shifted from the device into the room \\
\hline & AUG3 & The objects I see on the screen was real \\
\hline \multirow{2}{*}{ Utilitarian Benefits } & UTI1 & This app is useful \\
\hline & UTI2 & This application supported me to understand the features of the shoe \\
\hline \multirow{3}{*}{ Hedonic Benefits } & HED1 & This app is entertaining \\
\hline & HED2 & I had fun when I used this app \\
\hline & HED3 & This app is a good time killer \\
\hline \multirow{4}{*}{ Decision Comfort } & DEC1 & I feel confident with choosing this shoe model \\
\hline & DEC2 & I feel good about selecting this shoe model \\
\hline & DEC3 & I am okay with choosing this shoe model. \\
\hline & DEC4 & I feel very comfortable with the selection I have made \\
\hline \multirow{3}{*}{ Perceived Risk } & RIS1 & Buying decision of this product is extremely risky \\
\hline & RIS2 & Buying decision for this product is very important \\
\hline & RIS3 & I am very worried about the buying decision of this product \\
\hline \multirow{3}{*}{ Purchase Intentions } & INT1 & I will choose this one for sports shoe needs in the coming days \\
\hline & INT2 & If I needed some sports shoe last year, I would have selected this shoe \\
\hline & INT3 & In the next year, if I need some sports shoe, I will select this one \\
\hline
\end{tabular}

Scale validations and reliability checks in the study were tested through the confirmatory factor analysis (CFA). Perceived augmentation, utilitarian benefits, hedonic benefits, decision comfort, perceived risk and purchase intentions were the variables included into the confirmatory factor analysis. The construct validity of the model was confirmed with the production of satisfactory fit indices $(X 2 / D F=1.739, C F I=0.962$, IFI=0.962, RMSEA $=0.072$ ) in line with the acceptable limits suggested by previous studies in the literature. Based on the previous studies in the literature, the minimum acceptable limits for the fit indices should be below the level of 3 for the CMIN/DF ratio, scores above 0.9 for the CFI and IFI and finally, below the score of 0.10 for the RMSEA (Bagozzi \& Yi, 1990). The construct validity is also confirmed with the scores of intra-factor loadings above 0.5 which is the minimum acceptable limit of threshold level requiring no adjustment for scale items. Table 2 presents the intra-factor loadings of all variables included into the CFA. 
Table 2: Factor Loadings of Scale Items

\begin{tabular}{lccc}
\hline \multirow{2}{*}{ Scale } & Items & Standardized Factor Loads & Unstandardized Factor Loads \\
\hline \multirow{3}{*}{ Perceived Augmentation } & AUG1 & 0.727 & 1.000 \\
& AUG2 & 0.811 & 1.257 \\
& AUG3 & 0.755 & 0.984 \\
\hline \multirow{2}{*}{ Utilitarian Benefits } & UTI1 & 0.951 & 1.000 \\
& UTI2 & 1.001 & 1.104 \\
\hline \multirow{3}{*}{ Hedonic Benefits } & HED1 & 0.853 & 1.000 \\
& HED2 & 0.815 & 1.257 \\
& HED3 & 0.874 & 0.984 \\
\hline \multirow{3}{*}{ Decision Comfort } & DEC1 & 0.681 & 1.000 \\
& DEC2 & 0.916 & 1.402 \\
& DEC3 & 0.857 & 1.400 \\
& DEC4 & 0.845 & 1.236 \\
\hline \multirow{3}{*}{ Perceived Risk } & RIS1 & 0.903 & 1.000 \\
& RIS2 & 0.959 & 1.338 \\
& RIS3 & 1.013 & 1.584 \\
\hline \multirow{2}{*}{ Purchase Intention } & INT1 & 0.853 & 1.000 \\
& INT2 & 0.870 & 1.007 \\
\hline p<0.01 for all items & INT3 & 0.883 & 1.016 \\
\hline
\end{tabular}

In addition to the construct validity, the convergent validities of all scales employed in the study were also checked by calculating Average Variance Extracted (AVE) scores for each scale. The computed scores of AVE are found to be above the minimum acceptable level of 0.50 (Byrne, 2010). Following the construct and convergent validity checks, several reliability checks were also conducted to confirm the composite and internal reliability of the scales employed in the study. The results of the composite and internal reliability check also yielded to scores above the minimum level suggested by the previous studies (Fornell \& Larcker, 1981). Table 3 presents the validity and reliability checks of all scales employed in the study.

Table 3: Scale Validation and Reliability Checks

\begin{tabular}{|lcccccc|}
\hline Dimensions & $\mathbf{1}$ & $\mathbf{2}$ & $\mathbf{3}$ & $\mathbf{4}$ & $\mathbf{5}$ & $\mathbf{6}$ \\
\hline Perceived Augmentation & $(.765)$ & & & & & \\
Utilitarian Benefits & $0.341^{* *}$ & $(.976)$ & & & & \\
Hedonic Benefits & 0.033 & 0.108 & $(.848)$ & & & \\
Decision Comfort & $0.460^{* *}$ & $0.580^{* *}$ & $0.169^{*}$ & $(.829)$ & & \\
Perceived Risk & $-0.325^{* *}$ & -0.154 & 0.107 & $-.294^{* *}$ & $(.959)$ & \\
Purchase Intention & $0.661^{* *}$ & $0.318^{* *}$ & $0.212^{*}$ & $0.527^{* *}$ & $-0.443^{* *}$ & $(.869)$ \\
\hline Composite Reliability & .809 & .976 & .884 & .897 & .972 & .902 \\
AVE Scores & .585 & .953 & .719 & .688 & .920 & .755 \\
Cronbach $\alpha$ & .801 & .975 & .872 & .892 & .963 & .902 \\
\hline$* *$ Significant at the 0.01 level; *Significant at the 0.05 level & & & & \\
\hline
\end{tabular}

\section{FINDINGS AND DISCUSSIONS}

\subsection{Findings}

The Structural Equation Modeling (SEM) analysis was utilized to test the hypotheses proposed in the research model. Parallel to the CFA results, computation of all fit indices yielded satisfactory scores indicating a good fit of the model (X2/DF $=2.066$, 
$\mathrm{CFI}=0.942, \mathrm{IFI}=0.942, \mathrm{RMSEA}=0.086)$. The path estimations yielded statistically significant results supporting all hypothesis proposed. Overall, the results confirmed three factors, namely perceived augmentation, utilitarian benefits, and hedonic benefits as the contributing factors to the decision comfort perceived by the consumers. In turn, decision comfort is found to be a significant influencer of purchase intentions towards the product evaluated using the AR app. In addition to these effects, purchase intention is found to have a negative impact on the perceived risk level and perceived risk is found to also have a strong negative influence on purchase intentions. In the light of these results, H1, H2, H3, H4, H5 and H6 were supported. The final structural model and supported hypothesis with statistically significant paths and associated standardized coefficients are presented in Figure 3.

Figure 3: Test Results of the Structural Model

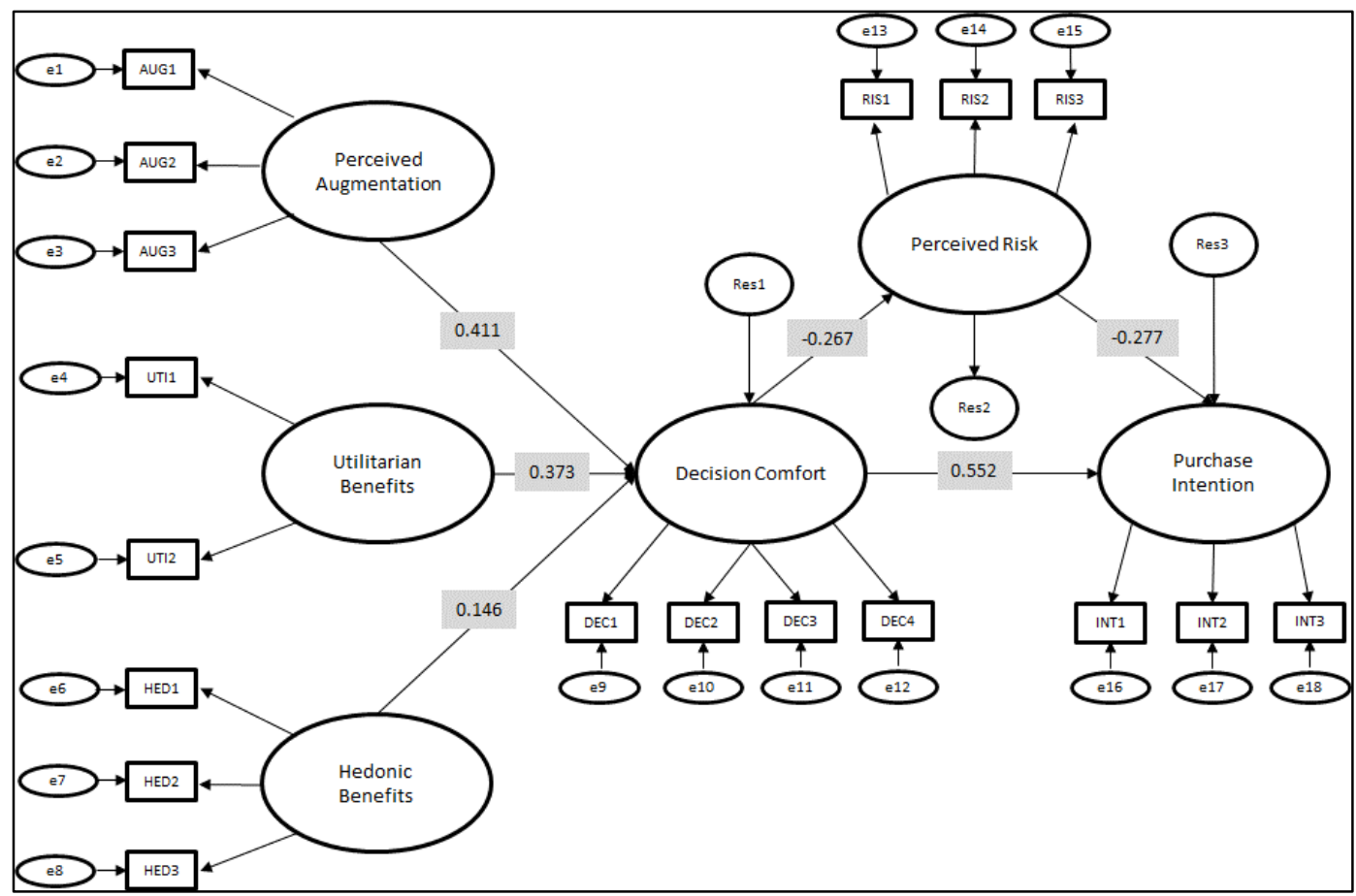

In order to check the mediating role of perceived risk on the influence of decision comfort on the purchase intentions, three effects, namely total, direct, and indirect effects of decision comfort on the purchase intentions were calculated and analyzed. The constituent paths for the three effects, namely total, direct, and indirect effects are presented in Figure 4. 
Figure 4: Total, Direct and Indirect Effects of Decision Comfort on Purchase Intentions

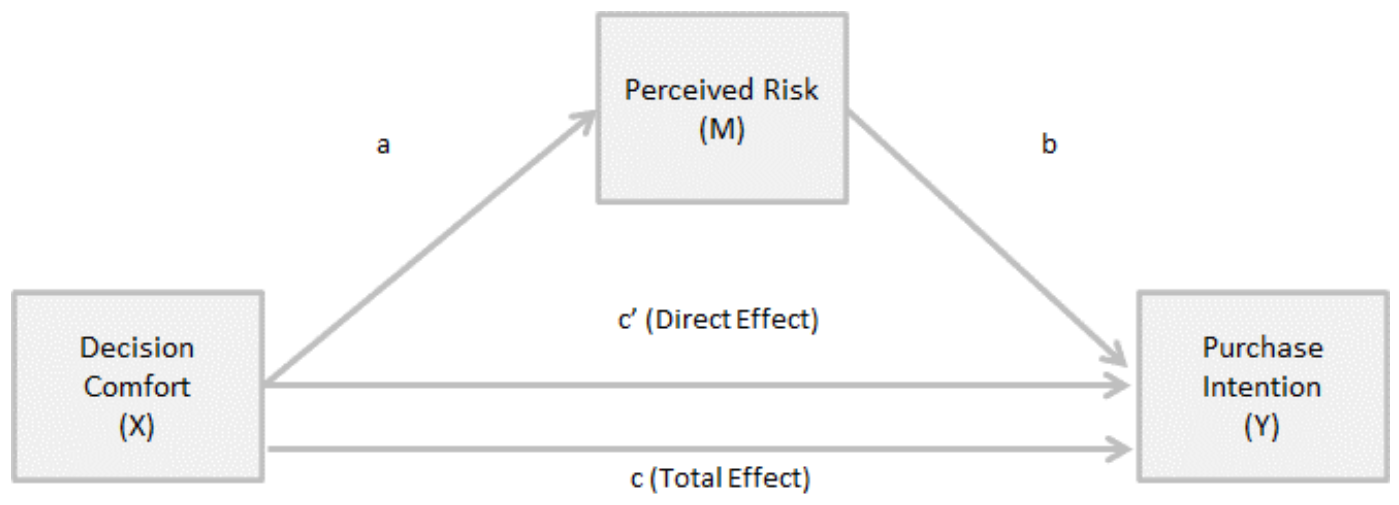

The computation and standardized coefficients of total, direct as well as indirect effects of decision comfort on purchase intentions are presented in Table 4. The letter " $c 1$ "represents the model which direct effect of decision comfort on the purchase intention is computed. The letter " $a$ " represents the direct effect of decision comfort on perceived risk, and the letter "b" represents the direct effect of perceived risk on purchase intention. The indirect effect of decision comfort on purchase intention through perceived risk is calculated with the multiplication of these two direct effects ( $a * b)$. Finally, the letter "represents the model which total effect of decision comfort on the purchase intention is computed. The total effect of decision comfort on purchase intention is the computed as the sum of direct and indirect effect of decision comfort on purchase intention, which can be formulized as $c=[c 1+(a * b)]$. The results of the computation for the total, direct and indirect effects are presented in Table 4.

Table 4: Total, Direct and Indirect Effects of Decision Comfort on Purchase Intentions

\begin{tabular}{cccccc}
\hline & \multicolumn{2}{c}{ Decision Comfort } & - & & \\
Model & Effect Type & Estimate & Boot LLCl & Boot ULCl & P \\
\hline 1 & Total Effect & 0.677 & 0.382 & 0.964 & .001 \\
\hline 2 & Direct Effect & 0.597 & 0.306 & 0.898 & .001 \\
\hline 3 & Indirect Effects & 0.080 & 0.029 & 0.174 & .001 \\
\hline
\end{tabular}

The direct effect of decision comfort on purchase intentions presented in Model 2 was tested and confirmed previously leading to the support of H5. On the other hand, Model 3 presents the indirect effect of decision comfort on purchase intentions through perceived risk. The results of the analysis confirmed a significant indirect effect since the confidence intervals $(\mathrm{Cl})$ reported do not include any zero value within the lower and upper confidence intervals. Confidence Interval (Cl) scores reported in the $95 \%$ level between 0.029 and 0.174 , confirmed the significant indirect effect of decision comfort on purchase intentions through perceived risk. However, since the direct effect of decision comfort on purchase intentions does not turn into insignificant direct effect and generates a weaker but significantly positive effect when perceived risk mediates this relationship, it can be concluded that the mediating effect of perceived risk is a partial one. In the light of this result, $\mathrm{H} 7$ is partially accepted. The results of all hypothesis tests are summarized in Table 5. 
Table 5: Results of the Hypothesis Testing

\begin{tabular}{|llccc|}
\hline \# & Relationships & $\begin{array}{c}\text { Standardized } \\
\text { Coefficients }\end{array}$ & $\begin{array}{c}\text { Unstandardized } \\
\text { Coefficients }\end{array}$ & Result \\
\hline H1 & Perceived Augmentation $\rightarrow$ Decision Comfort & $0.411^{* *}$ & $0.500^{* *}$ & Accepted \\
H2 & Utilitarian Benefits $\rightarrow$ Decision Comfort & $0.373^{* *}$ & $0.206^{*}$ & Accepted \\
H3 & Hedonic Benefits $\rightarrow$ Decision Comfort & $0.146^{*}$ & $0.212^{*}$ & Accepted \\
H4 & Decision Comfort $\rightarrow$ Perceived Risk & $-0.267^{* *}$ & $-0.245^{*}$ & Accepted \\
H5 & Decision Comfort $\rightarrow$ Purchase Intention & $0.552^{* *}$ & $0.597^{* *}$ & Accepted \\
H6 & Perceived Risk $\rightarrow$ Purchase Intention & $-0.277^{* *}$ & $-0.327^{* *}$ & Accepted \\
\hline & Mediating Role of Perceived Risk & Estimate & LLCl/ULCl & Result \\
\hline H7 & Decision Comfort $\rightarrow$ Perceived Risk $\rightarrow$ Purchase & $0.080^{* *}$ & $0.029 / 0.174$ & Partially \\
& Intention & & Accepted \\
\hline$* *$ Significant at the 0.01 level; $*$ Significant at the 0.05 level & & \\
\hline
\end{tabular}

\subsection{Discussion}

The two primary objectives of this study were first to identify the determinants of the factors which are expected to contribute to the decision comfort level of consumers and then to integrate the perceived risk construct into the influence of AR app generated comfort decision on consumer purchase intentions. The findings of the study confirmed the positive impact of perceived augmentation, utilitarian, and hedonic benefits on the decision comfort level of consumers. In line with the previous studies (Watson et al., 2020; Javornik et al. 2016), when consumers receive an authentic experience due to the higher levels of perceived augmentation, this generates a spatial presence feeling leading to the synchronization of digital stimulus and physical environment with higher levels of control facilitating the decision comfort. In addition to perceived augmentation, when utilitarian and hedonic benefits are perceived positively, consumers generate a more positive perception of decision comfort in their purchase decision process. These findings also find a correspondence and confirmation in the relevant literature (Poncin and Mimoun, 2014). As it is suggested by the previous studies (Hilken et al. 2017), when consumers mitigate the mental burden related to the imagination of the offered product in the physical environment with the decision comfort provided by the AR app, as the results of the study confirmed, this decision comfort provided positively influences the purchase intention of consumers. There are two important contributions of this study which need to be underlined. The first contribution is the finding related to the negative influence of decision comfort provided by the AR app on the risk perceptions of consumers. One of the important contributions of this study is the impact of decision comfort on perceived risk perceptions related to the product purchase situation. Due to the lack of studies in the literature which measure the impact of decision comfort on perceived risk in AR enabled shopping context, this finding is a novel contribution to the literature. Similarly, a second important novelty provided by this study is the findings related to the significant mediating role of perceived risk on the influence of decision comfort on the purchase intentions.

There are also some important managerial implications which needs to be discussed. First of all, the main objective of providing an AR app in a retailing context is to facilitate the decision-making process for the consumers. Thus, any AR originated feature which empowers the decision comfort is expected to contribute to the core objective of using AR apps in retailing context. In this perspective, the findings clearly indicate that the augmentation performance of AR apps are critical to combine and synchronize the digital stimulus (product offered) and the physical environment, which eventually influences the decision comfort. This finding leads us to conclude that the augmentation quality of the AR app is critical for generating favorable consumer responses. On the other hand, there are also two other important factors which serve the same purpose: utilitarian and hedonic benefits provided by the AR app. Since utilitarian benefits, including functional and instrumental features, are important to facilitate the decisionmaking process, retailers need to be sensitive on the effectiveness and richness of functionality and features provided to the consumer by the AR app. Similarly, emotional engagement of consumers needs to be generated through the aesthetics, enjoyment-related and experiential benefits provided by the AR app. Overall, providing a decision comfort in order to generate a positive consumer response towards the product requires developing an AR app with superior augmentation quality and design elements. However, as one of the contribution of this study, perceived risk plays an important role in negatively affecting the 
positive influence of decision comfort provided by the AR app on the purchase intentions. In order to mitigate this negative impact of perceived risk, retailers need to support the decision process of consumers with additional marketing communication including the experiences of other consumers who purchased the products using the same AR app, the product return policy details, and other supporting applications provided by the retailer. Providing consumers with such additional information, which will be helpful to lower their perceived risk related to the product and purchase situation, will sustain the positive influence of decision comfort provided by the AR app.

\section{CONCLUSION}

This study contributed to the existing literature, first by confirming the factors which contribute to the decision comfort level of consumers and then by measuring the mediating role of perceived risk on the influence of decision comfort on consumer purchase intentions. However, there are some limitations to be mentioned in terms of the generalizability with regard to these results. First of all, the participants were selected from the universities and student population. In order increase the generalizability of the results, the sample may be chosen in a way to be more representative of the population. Secondly, in terms of research design, only one product category, sports shoe, is tested in this study and this generates a limitation for the generalizability of the results. In future studies, it is recommended to implement a cross-category research design including other product categories.

\section{REFERENCES}

Azuma, R., Baillot, Y., Behringer, R., Feiner, S., Julier, S., \& Maclntyre, B. (2001). Recent advances in augmented reality. IEEE Computer Graphics and Applications, November-December, 34-47.

Bauer, H. H., Falk, T., \& Hammerschmidt, M. (2006). eTransQual: A transaction process-based approach for capturing service quality in online shopping. Journal of Business Research, 59(7), 866-875.

Bauer, R. A. (1960). Consumer behavior as risk taking. In R. Hancock (Ed.), Dynamic marketing for a changing world. Proceedings of 43rd Conference, American Marketing Association, 389-398.

Beck, M., \& Crié, D. (2016). I virtually try it... I want it! Virtual fitting room: a tool to increase on-line and off-line exploratory behavior, patronage, and purchase intentions. Journal of Retailing and Consumer Services, 40(January 2018), 279-286.

Byrne, B. M. (2010). Structural equation modeling with AMOS. New York: Routledge Taylor \& Francis Group.

Campbell, M.C., \& Goodstein, R.C. (2001). The moderating effect of perceived risk on consumers' evaluations of product incongruity: preference for the norm. Journal of Consumer Research, 28 (December), 439-449.

Carmigniani, J., Furht, B., Anisetti, M.,Ceravolo, P., Damiani, E., Ivkovic, M., 2011. Augmented reality technologies, systems, and applications. Multimedia Tools Applications, 51, 341-377.

Childers, T. L., Carr, C. L., Peck, J., \& Carson, S. (2001). Hedonic and utilitarian motivations for online retail shopping behavior. Journal of Retailing, 77(4), 511-535.

Chitturi, R., Raghunathan, R., \& Mahajan, V. (2008). Delight by design: the role of hedonic versus utilitarian benefits. Journal of Marketing, 72(3), 48-63.

Dacko, S. G. (2016). Enabling smart retail settings via mobile augmented reality shopping apps. Technological Forecasting and Social Change, 124(November 2017), 243-256.

Davis, F. D. (1986). A technology acceptance model for empirically testing new end-user information systems: theory and results (PhD thesis) Massachusetts Institute of Technology, Sloan School of Management.

Domina, T., Lee, S.E., \& Mac Gillivray, M. (2012). Understanding factors affecting consumer intention to shop in a virtual world. Journal of Retail Consumer Services, 19(6), 613-620.

Donovan, R. J. \& Rossiter, J. R. (1982). Store atmosphere: an environmental psychology approach. Journal of Retailing, 58(1), 34-57.

Fiore, A. M., Kim, J., \& Lee, H.-H. (2005). Effect of image interactivity technology on consumer responses toward the online retailer. Journal of Interactive Marketing, 19(3), 38-53.

Fishbein, M., \& Ajzen, I., 1975. Belief, attitude, intention and behavior: an introduction to theory and research. Addison Wesley, Reading, MA.

FitzGerald, E., Ferguson, R., Adams, A., Gaved, M., Mor, Y., \& Thomas, R. (2013). Augmented reality and mobile learning: The state of the art. International Journal of Mobile and Blended Learning, 5(4), 43-58. 
Fornell, C. \& Larcker, D. (1981). Evaluating structural equation models with unobservable variables and measurement error. Journal of Marketing Research, 18(1), 39-50.

Gaudiosi, J. (2015). How augmented reality and virtual reality will generate $\$ 150$ billion in revenue by 2020 [WWW Document]. URL 〈http://fortune.com/2015/ 04/25/augmented-reality-virtual-reality/〉.

Hilken, T., Ruyter, K., Chylinski, M., Mahr, D., \& Keeling, D.I. (2017). Augmenting the eye of the beholder: exploring the strategic potential of augmented reality to enhance online service experiences. Journal of the Academy of Marketing Science, 45, 884-905.

Hong, I., \& Cha, H. S. (2013). The mediating role of consumer trust in an online merchant in predicting purchase intention. International Journal of Information Management, 33, 927-939.

Huang, T.-L. \& Liao, S.-L. (2017). Creating e-shopping multisensory flow experience through augmented-reality interactive technology. Internet Research, 27(2), 449-475.

Huang, T.-L. \& Liao, S. (2015). A model of acceptance of augmented-reality interactive technology: the moderating role of cognitive innovativeness. Electronic Commercial Research, 15(2), 269-295.

Huang, E. (2012). Online experiences and virtual goods purchase intention. Internet Research, 22(3), 252-274.

Jarvenpaa, S. L., \& Leidner, D. E. (1999). Communication and trust in global virtual teams. Organization Science, 10(6), 791-815.

Javornik, A. (2016a). Augmented reality: Research agenda for studying the impact of its media characteristics on consumer behavior. Journal of Retailing and Consumer Services, 30, 252-261.

Javornik, A. (2016b). It is an illusion, but it looks real! Consumer affective, cognitive, and behavioral responses to augmented reality applications. Journal of Marketing Management, 32(9-10), 987-1011.

Javornik, A., Rogers, Y., Moutinho, A.M., \& Freeman, R., (2016). Revealing the shopper experience of using a 'magic mirror' augmented reality make-up application. Proceedings of the 2016 ACM Conference on Designing Interactive Systems, 871-882.

Jin, S.-A.A. (2009). The roles of modality richness and involvement in shopping behavior in 3D virtual stores. Journal of Interactive Marketing, 23(3), 234-246.

Kim, H.C., \& Hyun, M.Y. (2016). Predicting the use of smartphone-based augmented reality (AR): does telepresence really help? Computers in Human Behavior, 59(June 2016), 28-38.

Kim, A.J. \& Ko, E. (2012). Do social media marketing activities enhance customer equity? An empirical study of luxury fashion brand. Journal of Business Research, 65(10), 1480-1486.

Kim, J. \& Forsythe, S. (2008). Adoption of virtual try-on technology for online apparel shopping. Journal of International Marketing, 22(2), 45-59.

Klein, L. R. (2003). Creating virtual product experiences: The role of telepresence. Journal of Interactive Marketing, 17(1), 41-55.

Koller, M. (1988). Risk as a determinant of trust. Basic and Applied Social Psychology, 9(4), 265-276.

Kozinets, R.V., de Valck, K., Wojnicki, A.C., Wilner, S. J. (2010). Networked narratives: understanding word-of-mouth marketing in online communities. Journal of Marketing, 74, 71-89.

Lee, H.-H., Fiore, A.M. \& Kim, J. (2006). The role of the technology acceptance model in explaining effects of image interactivity technology on consumer responses. International Journal of Retail and Distribution Management, 34(8), 621-644.

Lombard, M., \& Snyder-Duch, J. (2001). Interactive advertising and presence: A framework. Journal of Interactive Advertising, 1(2), 56-65.

Markets and Markets. (2015). Augmented reality market worth 56.8 billion USD by 2020 [WWW Document]. URL 〈http://www.marketsandmarkets.com/ PressReleases/augmented-reality.asp〉.

Mehrabian, A. \& Russell, J.A. (1974). An approach to environmental psychology. MIT Press, Cambridge, MA.

Murray, K. B. (1991). A test of services marketing theory: consumer information acquisition activities. Journal of Marketing, 55(1), 11-25.

Olsson, T., Lagerstam, E., Kärkkäinen, T., \& Väänänen-Vainio-Mattila, K. (2013). Expected user experience of mobile augmented reality services: A user study in the context of shopping centres. Personal and Ubiquitous Computing, 17(2), 287-304.

Pantano, E. \& Servidio, R. (2012). Modeling innovative points of sales through virtual and immersive technologies. Journal of Retailing and Consumer Services, 19(3), 279-286.

Parker, J. R., Lehmann, D. R., \& Xie, Y. (2016). Decision comfort. Journal of Consumer Research, 43(1), $113-133$. 
Pavlou, P. A. (2003). Consumer acceptance of electronic commerce: Integrating trust and risk with the technology acceptance model. International Journal of Electronic Commerce, 7(3), 69-103.

Poncin, I., \& Mimoun, M. S. B. (2014). The impact of “e-atmospherics” on physical stores. Journal of Retailing and Consumer Services, 21(5), 851859.

Poushneh, A. \& Vasquez-Parraga, A.Z. (2017). Discernible impact of augmented reality on retail customer's experience, satisfaction, and willingness to buy. Journal of Retailing and Consumer Services, 34, 229-234.

Rauschnabel, P.A., Felix, R. \& Hinsch, C. (2019). Augmented reality marketing: How mobile AR-apps can improve brands through inspiration. Journal of Retailing and Consumer Services, 49(2019), 43-53.

Rauschnabel, P.A. (2018). Virtually enhancing the real world with holograms: an exploration of expected gratifications of using augmented reality smart glasses. Psychology and Marketing, 35(8), 557-572.

Riva, G., Baños, R.M., Botella, C., Mantovani, F., \& Gaggioli, A. (2016). Transforming experience: The potential of augmented reality and virtual reality for enhancing personal and clinical change. Frontiers in Psychiatry, 7(164), 1-14.

Rese, A., Baier, D., Geyer-Schulz, A., \& Schreiber, S. (2017). How augmented reality apps are accepted by consumers: A comparative analysis using scales and opinions. Technological Forecasting \& Social Change, 124 (2017), 306-319.

Spreer, P. \& Kallweit, K. (2014). Augmented reality in retail: assessing the acceptance and potential for multimedia product presentation at the PoS. SOP Transactions on Marketing Research, 1(1), 20-35.

Ström, R., Vendel, M., \& Bredican, J. (2014). Mobile marketing: a literature review on its value for consumers and retailers. Journal of Retailing and Consumer Services, 21, 1001-1012.

Van Noort, G., Voorveld, H.A.M., \& van Reijmersdal, E. A. (2012). Interactivity in brand web sites: cognitive, affective, and behavioral responses explained by consumers' online flow experience. Journal of Interactive Marketing, 26(4), 223-234.

Venkatesh, V., Thong, J.Y., \& Xu, X. (2012). Consumer acceptance and use of information technology: extending the unified theory of acceptance and use of technology. MIS Quarterly, 36(1), 157-178.

Watson, A., Bethan, A., \& Salavati, L. (2020). The impact of experiential augmented reality applications on fashion purchase intention. International Journal of Retail \& Distribution Management, 48(5), 433-451.

Wu, W., Lee, C., Fu, C. \& Wang, H. (2013). How can online store layout design and atmosphere influence consumer shopping intention on a website? International Journal of Retail \& Distribution Management, 42(1), 4-24.

Yadav, M. S., \& Pavlou, P. (2014). Marketing in computer-mediated environments: research synthesis and new directions. Journal of Marketing, 78, 20-40. 